\title{
Lumbar spinal stenosis causing intermittent priapism
}

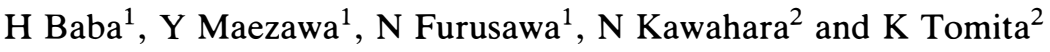 \\ ${ }^{1}$ Department of Orthopaedic Surgery, Fukui Medical School, Shimoaizuki 23, Matsuoka, Fukui 910-11; \\ ${ }^{2}$ Department of Orthopaedic Surgery, School of Medicine, Kanazawa University, Takaramachi 13-1, Kanazawa \\ 920, Japan
}

The current report concerns the unusual symptom of intermittent priapism, or what may be termed 'involuntary penile erection', associated with proven degenerative lumbar spinal stenosis. Seven patients who were treated for intermittent claudication and spontaneous priapism during walking were studied in terms of clinical presentation, imaging findings, and some electrophysiological testing. Varying degrees of walking and standing tolerance with these unusual symptoms appeared to be correlated with cauda equina constriction as was seen by radiological imaging. Although not statistically valid, external urethral sphincter evoked electromyography suggested the possibility of monitoring the unusual symptom during walking. Surgical spinal decompression is recommended to alleviate this symptom and the claudication.

Keywords: lumbar spinal stenosis; sacral nerves; priapism; involuntary penile erection; somatosensory evoked potentials; evoked electromyograms

\begin{abstract}
Introduction
Lumbar spinal stenosis causes a variety of neurological problems from radiculopathy alone to serious cauda equina symptoms involving sacral nerve root dysfunction. The degree of neurological compromise varies in conjunction with the modality of mechanical compression by the hypertrophied posterior elements of the lumbosacral spine on the neural tissues. Other factors contributing to the intermittent symptoms may be a disturbed arterial blood supply and venous congestion of the cauda equina during walking, and it is this aspect of the research that is now receiving much interest. As can be imagined, the serious sphincter and other autonomic dysfunctions can cause much suffering to the patient. The reported incidence of bladder and bowel dysfunction in symptomatic lumbar spinal stenosis accounts for $7.7-18 \%$ and sexual difficulty for $5.8-6.6 \% .{ }^{1-3}$ Intermittent priapism during walking, ${ }^{4-10}$ an unusual phenomenon seen in a patient with a narrowed lumbar spinal canal, is a confidential issue that may often miss the notice of the attending physician, but in our experience, ${ }^{11}$ the patient's complaint about this problem was comparable to the leg symptoms or sometimes more. In this article, we describe the clinical presentation and range of symptoms and the relevant electrophysiological tests concerning this issue, together with a discussion of its possible neurological aetiology.
\end{abstract}

\section{Patients and methods}

Patients and neurological assessment

Between 1983 and 1993, some 564 patients with symptomatic lumbar spinal stenosis have been admitted to our hospitals for surgical or conservative treatment. Based on the classification by Arnoldi et al, ${ }^{12}$ the patients, consisting of 389 men and 175 women, were assessed as seven congenital, 492 degenerative, 13 iatrogenic, 48 spondylolitic (isthmic), and four miscellaneous. Thirteen (3\%) of the male patients complained of intermittent priapism during walking, with varying degrees of walking tolerance or barely maintaining a standing position, and other situations that possibly caused an overload on the lower lumbar spine. Seven of the 13 cases complicated with intermittent priapism completed the current investigation. They ranged in age from 53 to 71 years and had an average disease history of 3.0 years. They showed a variety of neurological symptoms related to lumbar spinal stenosis, including intermittent claudication, but urological studies showed no evidence of a neuropathic bladder or of significant prostate hypertrophy requiring surgical intervention. One- or two-level bilateral partial laminectomy (wide fenestration) such as was recently reported by Aryanpur and Ducker ${ }^{13}$ had been performed in six patients; one patient (case 5) who had segmental instability was operated on by incorporating a Cotrel-Dubousset transpedicular screw arrangement with a posterolateral fusion for a grade I degenerative spondylolisthesis. One patient refused surgery. Intermittent difficulty in walking was simply assessed postoperatively as follows: improved, ie no claudication or walking tolerance doubled or even further improved without support; unchanged, ie walking tolerance less than doubled but still occurring; or worsened, ie walking tolerance decreased when compared with that present preoperatively or becoming non-ambulatory. Patients were followed up for 0.8 to 5.3 years (average, 3.3 years). 
Radiological examination

Radiological imaging included conventional radiography, myelography, computed tomography myelography, and magnetic resonance imaging (MRI). We used a 1.5 Tesla Signa System (General Electric, Milwaukee, WI, USA) for the MRI examinations before surgery and at follow-up. Our previous observation suggested the possible role of lumbar arachnoiditis at the level of stenosis in those with intermittent and spontaneous priapism ${ }^{11}$ and thus, in the present work, we studied the morphological changes seen in MRI. Based on the definition by Ross, ${ }^{14}$ these changes suggesting arachnoiditis were classified as follows: type I, large conglomerations of the cauda equina reside centrally in axial T1-weighted sequences and clump in T2-weighted MRI; type II, the cauda equina clump heavily and adhere peripherally to the meninges in T1-weighted MRI and T2-weighted sequences have the appearance of an 'empty thecal sac;' and type III, an increased soft tissue signal within the thecal sac in T1-weighted MR images, suggesting obliteration of most of the subarachnoidal space. When an MRI showed that the cauda equina nerve roots form a smooth crescent following the curvature of the posterior thecal sac, this was defined as normal. An axial MRI at the level of a total block in the preoperative myelogram may show a coalescence of the cauda equina and thus, in such a patient examination was carried out at the levels immediately above and below the level of the total block.

\section{Electrodiagnosis}

Electrophysiological tests included pudendal somatosensory evoked potentials (SEPs) monitoring, external urethral sphincter evoked electromyography (EMG), and bulbocavernosus reflex latency measurement. Using the method of Haldeman et al, ${ }^{15}$ pudendal SEPs were elicited unipolarly from a silver-chloride disc slectrode placed at $\mathrm{Cz}^{\prime}(3 \mathrm{~cm}$ posterior to $\mathrm{Cz})$ with a :eference electrode at Fpz' $(2 \mathrm{~cm}$ posterior from Fpl to Fz) following stimulation of the dorsal nerve of the senis with custom-made ring electrodes each $3 \mathrm{~cm}$ ipart: stimulus intensity, 15 to 45 volts; frequency, $2 \mathrm{~Hz}$; and duration of the rectangular pulse, $0.2 \mathrm{~ms}$. Responses occurring within $100 \mathrm{~ms}$ after the triggered stimuli were amplified by a DISA $15 \mathrm{CO} 4$ (Dantec DISA, Scovlunde, Denmark) with a bandpass of $10-2,000 \mathrm{~Hz}$, and averaged 256 times with a DISA 1500 digital EMG system. Major peaks appeared consecutively and the evoked responses were identified as N10, P41, N50, P68, and P88: the first three peaks were analysed before treatment and 2 weeks postoperatively or after the initiation of conservative therapy.

External urethral sphincter evoked EMGs were recorded using a custom-made bipolar silver electrode embedded on the outside wall of a urinary catheter (French size 14 or 16), located at the muscle and confirmed by an image intensifier, following the electrical stimulation of the spinal cord at the T12-L1 level with an indwelling epidural catheter electrode (UKG100-2PMW, Unique Medical, Tokyo, Japan) which we have been currently using for monitoring spinal cord evoked potentials. ${ }^{16}$ Using a Medelec ER94a System (A Vickers Healthcare Co, Woking, Surrey, UK), the evoked EMGs were recorded 1 day before surgery, intraoperatively after decompression, and 2 weeks after surgery or the initiation of conservative therapy. The stimulation setups were as follows: intensity, supramaximal ranging from 25 to 70 volts; frequency, $10 \mathrm{~Hz}$; and duration, $0.2 \mathrm{~ms}$. Recording and summation conditions were as follows: bandpass, 2 to $2,000 \mathrm{~Hz}$; analysis time, $50 \mathrm{~ms}$; and average, 64 times. No muscle relaxant was used for the intraoperative evoked EMGs in monitoring except for succinylcholine $1 \mathrm{mg} \mathrm{kg}^{-1}$ body weight at the time of intubation and an initial administration of vecuronium bromide (Musculax) $0.1 \mathrm{mg} \mathrm{kg}^{-1}$ body weight at the beginning of ethrane anaesthesia.

Using a DISA 1500 EMG system and a modification of the method reported by Siroky et al, ${ }^{17}$ the bulbocarvernosus reflex latency was measured before treatment and 2 weeks after surgery or the initiation of conservative therapy in case 1 . Electrical stimulation was provided by means of ring electrodes around the penis and reflexogenic waves were elicited by a concentric surface electrode placed cutaneously over the bulbocavernosus muscles. The stimulation conditions were set up as follows: intensity, 30 to 55 volts; frequency, $5 \mathrm{~Hz}$; and duration, $0.2 \mathrm{~ms}$. The recording conditions were set up as follows: bandpass, $2-2,000 \mathrm{~Hz}$; analysis time, $100 \mathrm{~ms}$; and average, 64 times. The initial negative deflection of the evoked response was defined as the bulbocavernosus reflex wave and its peak latency was measured. All of the electrophysiological examinations except those for intraoperative monitoring were performed in the airconditioned central clinical laboratory of the University Medical Centre and were tested five times following the conditioning trial. The median value was statistically analysed by Student's $t$ test, with a $P$ value less than 0.05 viewed as significant.

\section{Results}

\section{Clinical presentation}

Table 1 gives a summary of the clinical presentations. The patients showed varying walking tolerance at a distance from 50 to 350 metres (3-15 min) with intermittent and spontaneous priapism; four patients had priapism when standing for a while with their lower back in extended positions (Figures 1a, b). Two patients showed the phenomena when squatting or on the lavatory. Six patients demonstrated objective symptoms of sacral nerve dysfunction such as a hypoactive Achilles tendon reflex, sensory disturbance below the S1 distribution, and perianal and perineal pain even at rest, but these symptoms were not significant. Three patients had no signs or symptoms of sciatica. No evidence of a possible correlation between priapism and the duration of the disease and walking tolerance was noted. Four patients $(3,5,6$, and 7$)$ complained of painful priapism when walking. The duration of the priapism varied from approximately $1 \mathrm{~min}$ to $3 \mathrm{~min}$, but 
Table 1 Clinical summary of seven patients with intermittent priapism

\begin{tabular}{|c|c|c|c|c|c|c|}
\hline Patient & Age & $\begin{array}{l}\text { Duration of } \\
\text { history (years) }\end{array}$ & $\begin{array}{l}\text { Walking tolerance } \\
\text { metres (min) }\end{array}$ & Priapism & Sacral nerve symptoms & Remarkable leg symptoms \\
\hline 1 & 62 & 4.0 & $150(15)$ & Walking; standing for $3-5 \mathrm{~min}$ & Hypoactive ATR (R) & None \\
\hline 2 & 63 & 3.5 & $80(3)$ & Walking; playing golf & None & $\begin{array}{l}\text { Radicular pain in bilateral L4 } \\
\text { and L5 dermatome areas }\end{array}$ \\
\hline 3 & 68 & 5.5 & $300(8)$ & $\begin{array}{l}\text { Walking; standing } \\
\text { (occasionally) }\end{array}$ & $\begin{array}{l}\text { Hypoactive ATR (L), } \\
\text { hypaesthesia of S1 (L) and } \\
\text { S1-S4 (R) areas }\end{array}$ & Hypaesthesia of L5 area (L) \\
\hline 4 & 53 & 1.8 & $200(12)$ & Walking; squatting; standing & Hypaesthesia bilaterally in soles & None \\
\hline 5 & 71 & 3.9 & $50(3)$ & $\begin{array}{l}\text { Walking; standing; } \\
\text { straightening the lower back } \\
\text { (occasionally) }\end{array}$ & $\begin{array}{l}\text { Perineal pain even at rest; sense } \\
\text { of urination on walking; sensory } \\
\text { disturbance below S1 }\end{array}$ & $\begin{array}{l}\text { Bilateral leg pain at rest ( } \mathrm{L} 4 \\
\text { and L5 areas); positive } \\
\text { Lasegue test (bilateral) }\end{array}$ \\
\hline 6 & 64 & 1.3 & $130(8)$ & $\begin{array}{l}\text { Walking; when defecating in } \\
\text { lavatory }\end{array}$ & $\begin{array}{l}\text { Numbness at perianal and } \\
\text { perineal area; bilaterally } \\
\text { hypoactive ATRs }\end{array}$ & None \\
\hline 7 & 59 & 0.7 & $350(14)$ & Walking & Numbness in soles & Bilateral sciatica on walking \\
\hline
\end{tabular}

ATR $=$ Achilles tendon reflex $; \mathrm{R}=$ right $; \mathrm{L}=\mathrm{Left}$

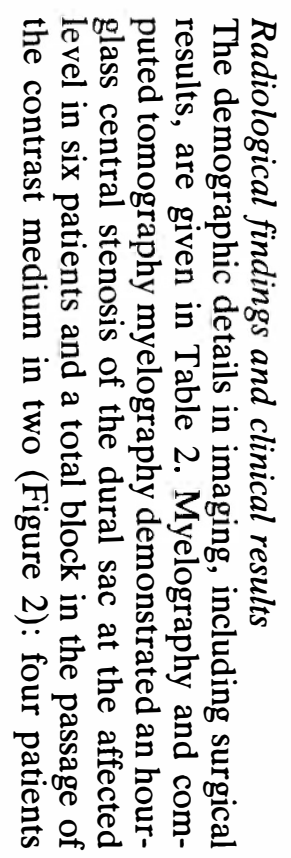

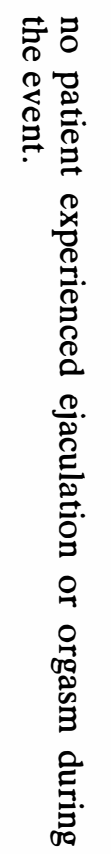

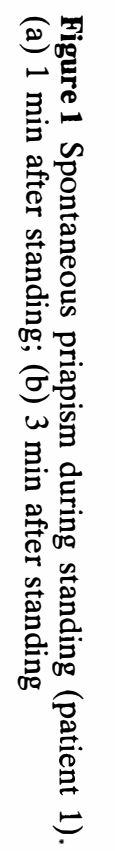

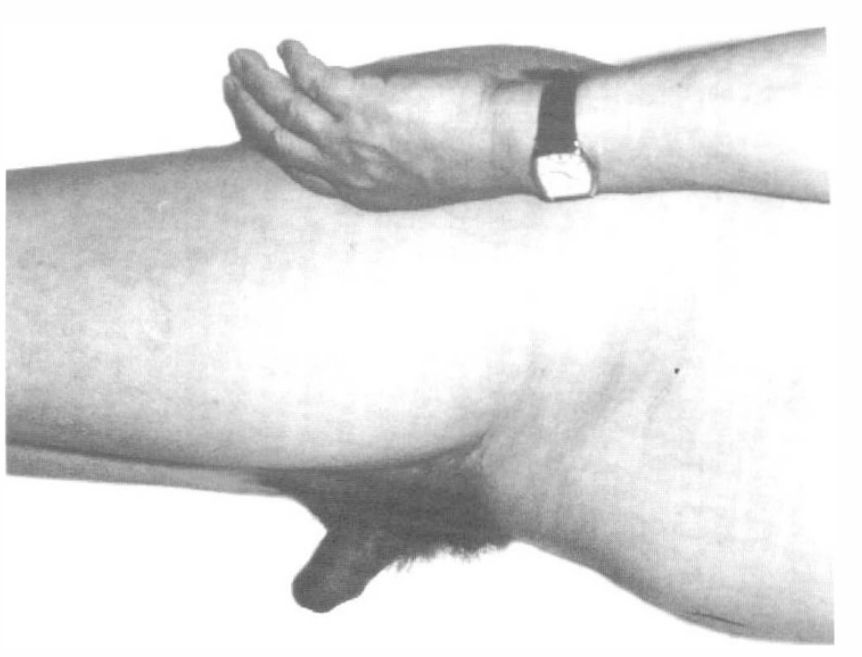


Table 2 Radiological findings and surgical results

\begin{tabular}{|c|c|c|c|c|c|c|c|}
\hline Patient & Type of stenosis & Myelogram & $\begin{array}{c}M R I \\
\text { (preoperative/at follow-up) }\end{array}$ & Treatment & $\begin{array}{l}\text { Postoperative } \\
\text { claudication }\end{array}$ & $\begin{array}{l}\text { Priapism at } \\
\text { follow-up }\end{array}$ & $\begin{array}{l}\text { Follow-up } \\
\text { (years) }\end{array}$ \\
\hline 1 & Degenerative (central) & $\begin{array}{l}\text { Hour-glass stenosis } \\
\quad(\mathrm{L} 3-4, \mathrm{~L} 4-5)\end{array}$ & Type II/Type II & TENS; epidural steroids & Unchanged & Unchanged & 5.3 \\
\hline 2 & Degenerative (central) & $\begin{array}{l}\text { Hour-glass stenosis } \\
\quad(\mathrm{L} 3-4, \mathrm{~L} 4-5)\end{array}$ & Normal/Normal & $\begin{array}{l}\text { Partial laminectomy } \\
\quad(\mathrm{L} 3-4, \mathrm{~L} 4-5)\end{array}$ & Improved & Improved & 4.8 \\
\hline 3 & Degenerative (central) & $\begin{array}{l}\text { Hour-glass block at } \mathrm{L} 3-4 \\
\text { and total block at } \\
\text { L4-5 }\end{array}$ & Type I/Type Ia & $\begin{array}{l}\text { Partial laminectomy } \\
\quad(\text { L4-5) }\end{array}$ & Improved & Improved & 3.9 \\
\hline 4 & $\begin{array}{l}\text { Degenerative (central } \\
\text { type) }\end{array}$ & $\begin{array}{l}\text { Hour-glass stenosis } \\
\quad(\text { L4-5) }\end{array}$ & Normal/Normal & $\begin{array}{l}\text { Partial laminectomy } \\
\text { (L4-5) }\end{array}$ & Improved & Improved & 3.5 \\
\hline 5 & $\begin{array}{l}\text { Degenerative } \\
\text { spondylolisthesis } \\
\text { (L4-5) }\end{array}$ & Total block (L4-5) & Type I/Type $I^{b}$ & $\begin{array}{l}\text { Partial laminectomy and } \\
\text { CD instrumentationc } \\
\text { (L4-5) }\end{array}$ & Unchanged & Improved & 2.9 \\
\hline 6 & $\begin{array}{l}\text { Degenerative } \\
\text { spondylolisthesis }\end{array}$ & $\begin{array}{l}\text { Hour-glass stenosis } \\
\quad(\text { L4-5) }\end{array}$ & Normal/Normal & $\begin{array}{l}\text { Partial laminectomy } \\
\quad(\text { L4-5) }\end{array}$ & Improved & Improved & 1.6 \\
\hline 7 & Degenerative (central) & $\begin{array}{l}\text { Hour-glass stenosis } \\
\quad(\text { L3 }-4<\text { L4-5) }\end{array}$ & Normal/Normal & $\begin{array}{l}\text { Partial laminectomy } \\
\quad \text { (L3-4, L4-5) }\end{array}$ & Improved & Improved & 0.8 \\
\hline
\end{tabular}

TENS $=$ transcutaneous electrical nerve stimulation

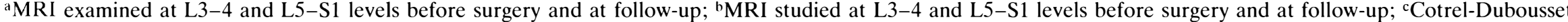
transpedicular screw arrangement with posterolateral fusion 


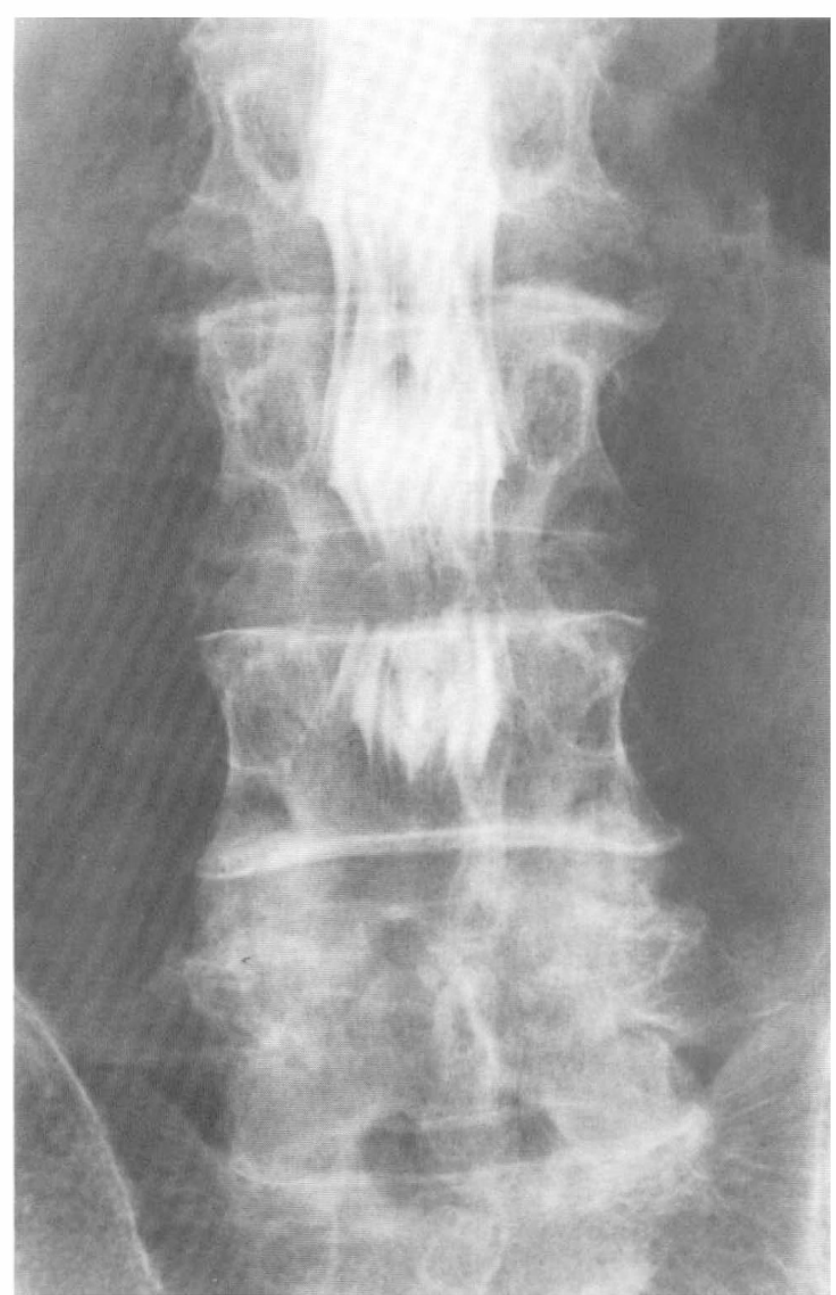

Figure 2 Myelogram showing hour-glass stenosis at L3-4 and a total block at L4-5 in patient 3

had two-level lesions. Three patients showed abnormal axial MRI images at the level of central stenosis (Figures $3 \mathrm{a}, \mathrm{b}$ ) or immediately above and below the level of the total block. None of these three patients showed an improvement or progressive change in MRI of the cauda equina at follow-up. Four patients had a normal MRI at the affected levels both before surgery and at follow-up. Intermittent leg symptoms improved in five of the six surgical cases, but priapism improved in all of the patients.

\section{Electrodiagnostic findings}

All data analysed for pudendal SEPs are shown in Table 3. The N10 component was absent preoperatively in all patients: the spike appeared postoperatively in two patients. No remarkable change occurred in the amplitude magnitude or the latency of the P41 component postoperatively in five cases. In one patient (1) treated with conservative therapy but still suffering from priapism, the latency of the N50 component was markedly delayed even though the amplitude remained essentially the same. Another patient who showed no a

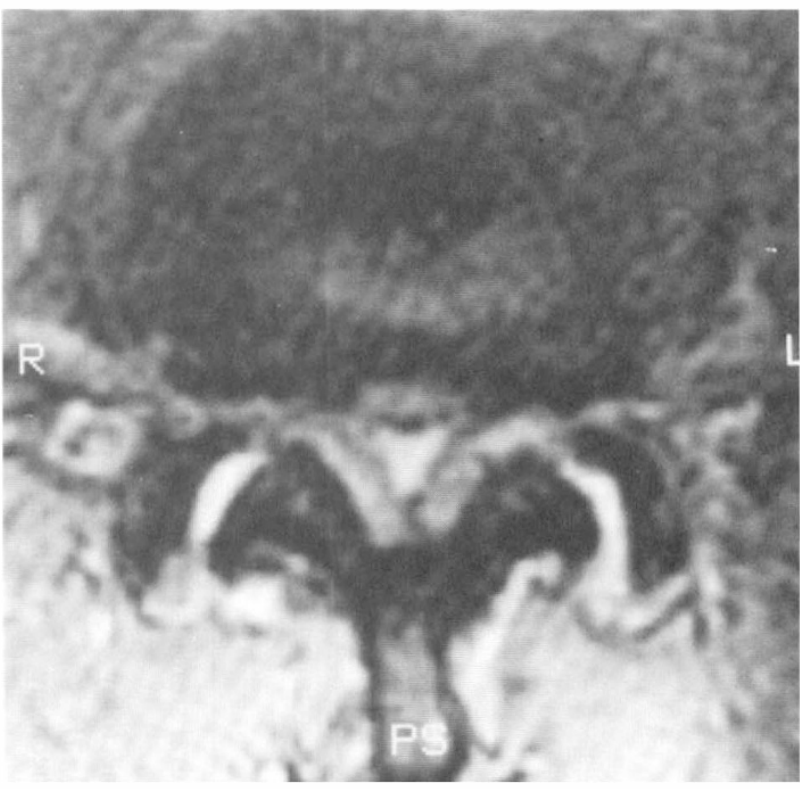

b

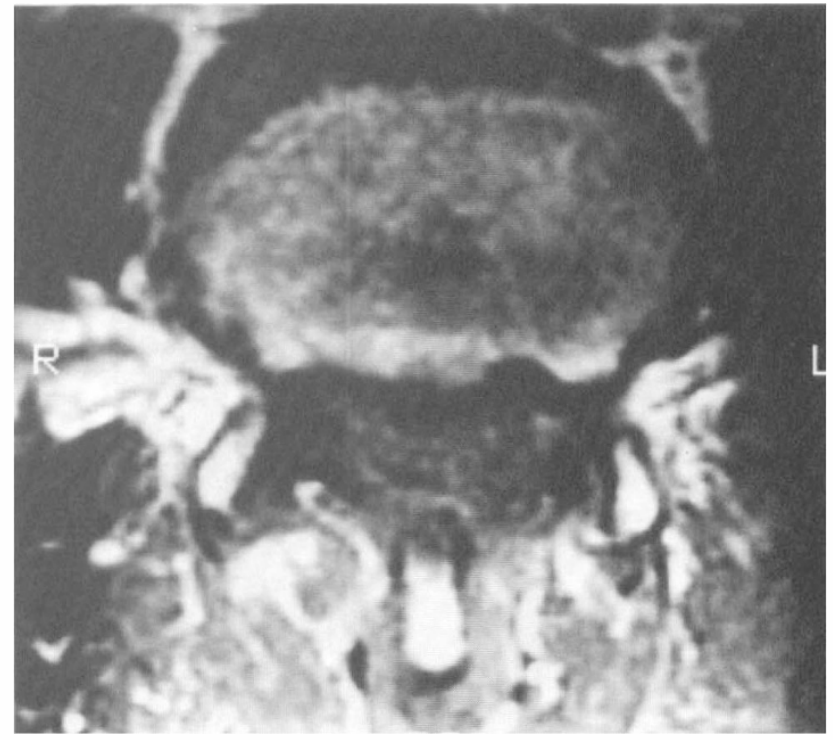

Figure 3 MRI for patient 3. (a) Preoperative; (b) at follow-up

improvement in leg symptoms despite the surgery was deemed satisfactory; all three components were unrecorded. The six patients with improved priapism did not show any remarkable abnormality in the P41 an N50 components.

External urethral sphincter evoked EMGs showed a slight increment in the amplitude intraoperatively after decompression and when the patient was allowed to stand or walk, but this was not statistically significant (Figure 4). The latency of the evoked EMGs was essentially the same throughout the examinations with the exception of one patient who showed an amplitude 
Table 3 Findings in the monitoring of pudendal somatosensory evoked potentials

\begin{tabular}{|c|c|c|c|c|c|c|c|c|c|c|c|c|c|}
\hline \multirow[t]{3}{*}{ Patient } & \multirow{3}{*}{$\begin{array}{l}\text { Height } \\
(\mathrm{cm})\end{array}$} & \multicolumn{4}{|c|}{ N10 component } & \multicolumn{4}{|c|}{ P4l component } & \multicolumn{4}{|c|}{ N50 component } \\
\hline & & \multicolumn{2}{|c|}{ Amplitude $(\mu V)^{a}$} & \multicolumn{2}{|c|}{ Latency (ms) } & \multicolumn{2}{|c|}{ Amplitude $(\mu V)^{b}$} & \multicolumn{2}{|c|}{ Latency (ms) } & \multicolumn{2}{|c|}{ Amplitude $(\mu V)^{c}$} & \multicolumn{2}{|c|}{ Latency (ms) } \\
\hline & & Befored & After & Before & After & Before & After & Before & After & Before & After & Before & After \\
\hline 1 & 162 & $(-)$ & $(-)$ & $(-)$ & $(-)$ & $(-)$ & $(-)$ & $(-)$ & $(-)$ & 1.5 & 1.8 & 58.3 & 71.4 \\
\hline 2 & 173 & $(-)$ & $(-)$ & $(-)$ & $(-)$ & 1.9 & 2.4 & 43.3 & 42.8 & 5.3 & 4.1 & 52.3 & 49.7 \\
\hline 3 & 158 & $(-)$ & $(-)$ & $(-)$ & $(-)$ & 1.5 & 2.8 & 39.6 & 39.3 & 3.9 & 4.7 & 49.6 & 48.7 \\
\hline 4 & 167 & $(-)$ & 0.4 & $(-)$ & 10.8 & 2.2 & 1.8 & 41.3 & 40.8 & 3.3 & 4.5 & $50.3^{\circ}$ & 49.7 \\
\hline 5 & 175 & $(-)$ & $(-)$ & $(-)$ & $(-)$ & $(-)$ & $(-)$ & $(-)$ & $(-)$ & $(-)$ & $(-)$ & $(-)$ & $(-)$ \\
\hline 6 & 161 & $(-)$ & 0.9 & $(-)$ & 12.3 & 3.7 & 4.9 & 45.3 & 44.4 & 4.6 & 2.8 & 54.1 & 55.9 \\
\hline 7 & 165 & $(-)$ & $(-)$ & $(-)$ & $(-)$ & 2.2 & 2.9 & 42.9 & 38.5 & 3.7 & 3.5 & 50.5 & 49.3 \\
\hline
\end{tabular}

aamplitude from baseline to N10 peak; 'bamplitude from baseline to $\mathrm{P} 41$ peak; 'P41-N50 peak-to-peak amplitude

Peak latency indicated dbefore treatment; ${ }^{2} 2$ weeks after surgery or the initiation of conservative treatment; $(-)$, spike absent

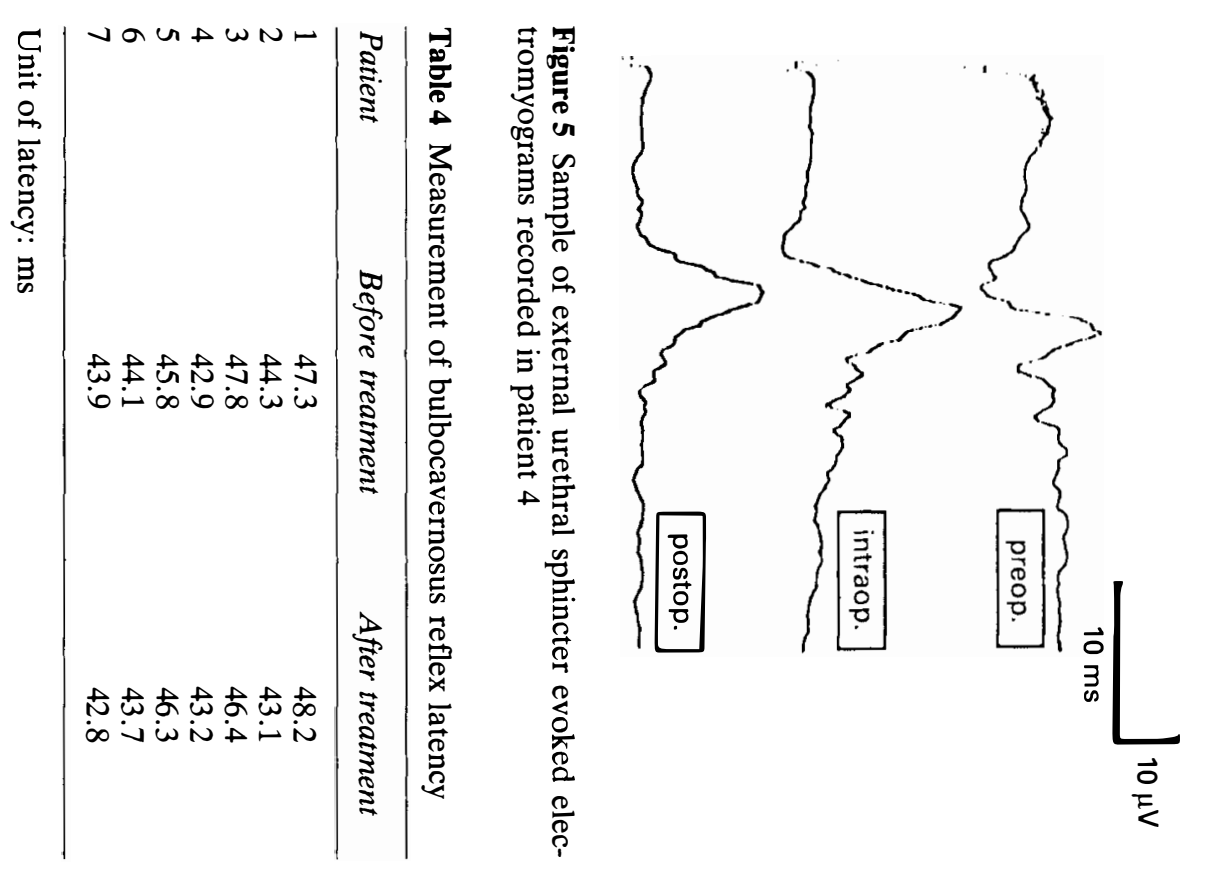

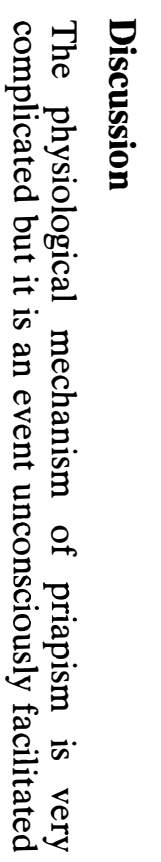
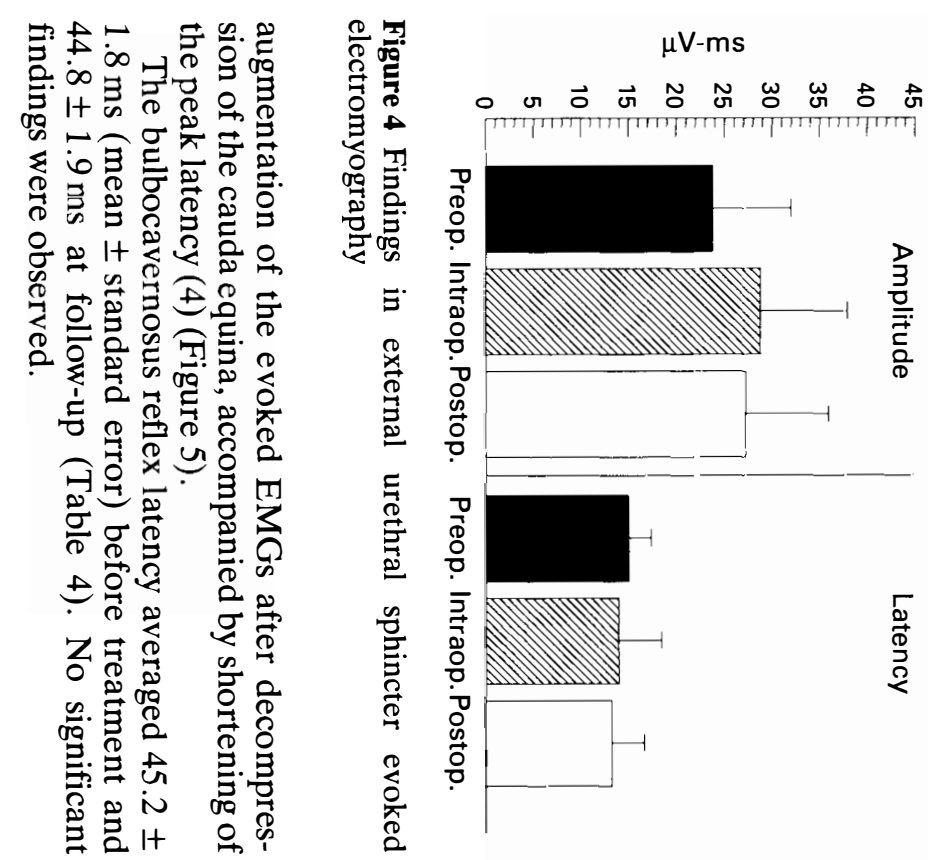
by a spinal reflex with the close control of supraspinal high centres such as the limbic system. ${ }^{18,19}$ It is well known that a patient whose spinal cord has been injured by an upper motor neuron lesion at any spinal level can have such reflex reactions. Even a patient with a lesion below T9 can have these reactions, leaving the upper splanchnic outflow intact. Both reflex and psychogenic factors contribute to this event, but intermittent and spontaneous erections without any sexual stimuli or amatory meditation or spinal cord disorders are unusual if the event is experienced during walking. Some reports describe this unusual symptom as an autonomic disorder associated with cauda equina compromise secondary to a narrowed lumbrosacral spinal canal. ${ }^{20,21}$ The disorder can be very troublesome and embarrassing for a relatively aged patient during walking, especially since it sometimes involves a great deal of pain in the penis and in the perineal area. Although the incidence of this disorder is low, care must be taken to enquire about its occurrence when taking a history of a patient complaining of possible sacral cauda equina symptoms.

The male sexual organs are innervated by two sets of autonomic fibres. The priapism reflex involves the pudendal nerve as an afferent parasympathetic pathway and the pelvic nerve as an efferent one under the control of the conus medullaris sacral reflex centre in the intermediolateral cells of the S2-4 segment located at the T11-L1 vertebral levels. Vasodilator fibres pass through to the corpora cavernosa, and the perineal branch of the pudendal nerve innervates the urethral sphincter and bulbocavernosus muscles which are involved in priapism. Sympathetic fibres from the hypogastric plexus connecting the dorsal nerve of the penis cause vasoconstriction in the corpora cavernosa and resultant relaxation of the erect penis. Priapism results from parasympathetic stimulation and is effected by engorgement of the corpora cavernosa of the penile tissue. A possible postulation is made for the increased parasympathetic efferent activity in the S2-4 cauda equina nerve roots within the narrowed thecal sac. Increased intrathecal pressure at the stenotic level and presumably disturbed circulation within the cauda equina during walking may contribute to the related parasympathetic hyperactivity. Shintani et al ${ }^{22}$ suggested that the mechanical impingement including the S2-4 nerve roots of the cauda equina within a narrowed lumbar spinal canal, especially when the lower back is extended, is responsible for increased parasymathetic activity. They believe that this is due to the direct effect of stenosis on the increased efferent activity. Using a specially-designed bladder control machine, developed by Brindley et al ${ }^{23}$ Fisher et al ${ }^{24}$ observed that electrical stimulation of the anterior cauda equina nerve roots of $\mathrm{S} 1-4$ occasionally produced a reflex erection even in paraplegic patients. These findings may suggest that the direct mechanical stimulation of the anterior sacral cauda equina nerve roots within the thecal sac can contribute to spontaneous priapism during walking. Hiraizumi et al postulate that somatic sensory afferent impulses being conveyed within the sacral or even the sciatic nerve roots may affect parasympathetic efferent activity within the conus medullaris spinal cord with unknown reflexogenic reactions. We maintain the postulation from our observations that most of these patients have some degree of pain in the penile and/or perineal regions prior to the occurrence of spontaneous priapism. However, the role of the sympathetic nerves in this regard is not known.

The cauda equina is considered to have a reduction in its neural conductivity during walking in relation to compromise of its intraneural circulation. ${ }^{26,27}$ Tamaki et $a l^{28}$ observed that there is a decrement of the cauda equina evoked action potentials when a patient experiences intermittent claudication whilst walking; the data suggest a functional compromise in neural conductivity of the cauda equina within the stenotic lumbar spine. Porter et $a l^{29}$ found that central canal stenosis, especially when it involves multiple segments, caused a serious deterioration in the blood circulation of the cauda equina. Olmarker et $a l^{30}$ suggest that a reduced blood flow will affect protein transport and nerve conduction of the cauda equina. Under these possibly compromised conditions of nerve conduction and blood circulation, the mechanisms determining why and how the suspected parasympathetic hyperactivity occurs is an issue requiring much further investigation.

Pudendal SEPs via somatic afferents of the S2-4 cauda equina and bulbocarvernosus reflex did not offer any suggestion about this mechanism in the present laboratory study but, hopefully, these may show disturbed neural conductivity when measured in a patient experiencing neurogenic claudication during walking, if the measurement is technically possible. Although statistically insignificant, external urethral sphincter evoked EMGs tended to show an increment in the amplitude after surgical decompression of the sacral cauda equina. A case presented showed an improvement in the latency of the evoked EMGs, which suggests a potential compromise of the nerves innervating the muscles, including autonomic function. The external urethral sphincter muscle is innervated by the pudendal nerve branches which arise in the anterior horns of the S2-4 segments of the spinal cord and which exit via the corresponding anterior roots (pudendal plexus). These fibres are considered to be motor nerves but are also considered to be in close connection with the parasympathetic system. If an excitatory stimulus comes from the intact spinal cord above the irritated cauda equina from the spinal canal by stenosis, it may be transiently and parasympathetically predominant over the sympathetic system because these two systems are expected to be in equilibrium even in a stenotic condition. In addition, a painful or excitatory somatic stimulus in the S2-4 areas will occur and may cause a reflex in the parasympathetic efferents and may cause spontaneous priapism, but this assumption should be studied further by neurophysiological investigations. The current preliminary investigation suggested that further neurophysiological testing during walking when a patient is having an erection would 
be more informative than would a non-dynamic laboratory study.

We originally expected that arachnoiditis had a possible effect on intermittent priapism, because most patients showed evidence of a severely constricted dural sac at the affected levels or of a total block on the myelograms. Three patients showed derangement of the cauda equina within the thecal sac at the level(s) most narrowed; others, however, showed a normal appearance even with severe stenosis. These findings suggest that a local event with clumping of the cauda equina at the stenotic level(s) may be of less concern with regard to spontaneous priapism. Mechanical compression of the cauda equina involving the S2-4 nerve roots can be more essential than arachnoiditis for the occurrence of intermittent and spontaneous priapism, as well as for claudication. From this point of view, surgical decompression adequately relieving the entire dural sac and contents from osseous and ligamentous entrapment is the treatment of choice. Although based on an experience involving only a small number of patients, we suggest that the unusual symptom of intermittent and spontaneous priapism (involuntary penile erection) is closely associated with central dural sac compression, and the mechanism for it is possibly increased reflex parasympathetic activity of the sacral cauda equina nerve roots and thus is further aggravated by the complication of a narrowed spinal canal.

\section{References}

1 Kikuchi S, Hasue M, Nishiyama $\mathrm{K}$, Ito $\mathrm{T}$. Anatomic and clinical studies of radicular symptoms. Spine 1984; 9: 23-30.

2 Kaneda K, Kazama H, Satoh S, Fujiya M. Follow-up study of medial facetectomies and posterolateral fusion with instrumentation in unstable degenerative spondylolisthesis. Clin Orthop 1986; 203: 159-167.

3 Baba H, Imura S, Tomita K. Surgical strategy and results of lumbar spinal stenosis. Abstract read at 6th International Conference on Lumbar Fusion and Stabilization, November 2-5 1993, Canberra, Australia.

4 Brish A, Lerner MA, Braham J. Intermittent claudication from compression of cauda equina by a narrowed spinal canal. $J$ Neurosurg 1964; 21: 207-211.

5 Ravindran M. Cauda equina compression presenting as spontaneous priapism. J Neurol Neurosurg Psychiatry 1979; 42: 280-282.

6 Merlini L, Ganata C, Prosperi P, Prosperi L. Intermittent claudication and priapism as a result of compression of the cauda equina caused by lumbar stenosis. Description of a case. Chir Organi Mov 1981; 67: 235-238.

7 Maurice-Williams RS, Marsh HT. Priapism as a feature of claudication of the cauda equina. Surg Neurol 1985; 23: 626-628.
8 Hopkins A, Clarke C, Brindley G. Erections on walking as a symptom of spinal canal stenosis. J Neurol Neurosurg Psychiatry 1987; 50: 1371-1374.

9 Coraddu $\mathrm{M}$ et al. Spontaneous priapism produced by stenosis of the lumbar canal. Acta Neurol (Napoli) 1989; 11: 428-433.

10 Garcia-Albea E, Palomo F, Tejeiro J. Erectiones durante la marcha y estenosis del canal lumbar. Revista Clinica Espanola 1990; 187: 65-67.

$11 \mathrm{Baba} \mathrm{H}$ et al. Intermittent priapism associated with lumbar spinal stenosis. Int Orthop 1994; 18: 150-153.

12 Arnoldi CC et al. Lumbar spinal stenosis and nerve root entrapment syndrome; definition and classification. Clin Orthop 1976; 115: 4-5.

13 Aryanpur J, Ducker TB. Multilevel lumbar laminotomies: an alternative to laminectomy in the treatment of lumbar stenosis. Neurosurgery 1990; 26: 429-433.

14 Ross JS. Inflammatory disease. In: Modic MT, Masaryk TJ, Ross JS (eds). Magnetic Resonance Imaging of the Spine. Year Book Medical: Chicago, 1989, pp 167-182.

15 Haldeman, Bradley WE, Bhatia NN, Johnson BK. Pudendal evoked responses. Arch Neurol 1982; 39: 280-283.

$16 \mathrm{Baba} \mathrm{H}$ et al. Spinal cord evoked potentials in thoracic myelopathy with multisegmental vertebral involvement. Spine 1992; 17: 1291-1295.

17 Siroky MB, Sax DS, Krane RJ. Sacral signal tracing: the electrophysiology of the bulbocavernosus reflex. J Urol 1979; 122: 661-664.

18 Weiss HD. The physiology of human penile erection. Ann Intern Med 76: 793-799.

19 DeGroat WC, Booth A. Physiology of male sexual function. Ann Intern Med 1980; 92: 329-331.

20 Laha RK, Dujovny M, Huang PS. Intermittent erection in spinal canal stenosis. J Urol 1979; 121: 123-124.

$21 \mathrm{Ram} \mathrm{KL}$ et al. Intermittent priapism in spinal canal stenosis. Spine 1987; 12: 377-378.

22 Shintani S, Shiozawa Z, Tsunoda S. Intermittent penile erection in lumbar spinal stenosis. J Neurol 1988; 235: 188-190.

23 Brindley GS, Polkey CE, Rushton DN. Sacral anterior root stimulators for bladder control in paraplegia. Paraplegia 1982; 20: $365-381$.

24 Fischer $\mathbf{J}$ et al. Sakrale Vorderwurzelstimulation zur Blasenentleerung nach Querschnittslaesionen. Zentralbl Neurochir 1993; 54: $77-79$.

25 Hiraizumi Y et al. Electrophysiologic evaluation of intermittent sacral nerve dysfunction in lumbar spinal canal stenosis. Spine 1993; 18: 1355-1360.

26 Ooi Y, Mita F, Satoh Y. Myeloscopic study on lumbar spinal canal stenosis with intermittent claudication. Spine 1990; 15: 544-549.

$27 \mathrm{Kim}$ NH, Yang IH, Song IK. Electrodiagnostic and histologic changes of graded caudal compression on cauda equina in dog. Spine 1994; 19: 1054-1062.

28 Tamaki $\mathrm{T}$ et al. Electrophysiological analysis on cauda equina intermittent claudication. Clin Orthop Surg (Tokyo) 1986; 21 : 513-517.

29 Porter RW, Ward D. Cauda equina dysfunction. The significance of two-level pathology. Spine 1992; 17: 9-15.

30 Olmarker K, Rydevik B. Single versus double level nerve root compression. An experimental study on the porcine cauda equina with analyses of nerve impulse conduction properties. Clin Orthop 1992; 279: 35-39. 